\title{
Time since death and decay rate constants of Norway spruce and European larch deadwood in subalpine forests determined using dendrochronology and radiocarbon dating
}

\author{
Marta Petrillo $^{1,2}$, Paolo Cherubini ${ }^{2}$, Giulia Fravolini ${ }^{4}$, Marco Marchetti ${ }^{4}$, Judith Ascher-Jenull ${ }^{5,6}$, Michael Schärer ${ }^{1}$, \\ Hans-Arno Synal ${ }^{3}$, Daniela Bertoldi ${ }^{7}$, Federica Camin ${ }^{7}$, Roberto Larcher $^{7}$, and Markus Egli ${ }^{1}$ \\ ${ }^{1}$ Department of Geography, University of Zurich, 8057 Zurich, Switzerland \\ ${ }^{2}$ WSL Swiss Federal Institute for Forest, Snow and Landscape Research, 8903 Birmensdorf, Switzerland \\ ${ }^{3}$ Laboratory of Ion Beam Physics, ETH Zurich, 8093 Zurich, Switzerland \\ ${ }^{4}$ Department of Bioscience and Territory, University of Molise, 86090 Pesche, Italy \\ ${ }^{5}$ Department of Agrifood and Environmental Science, University of Florence, 50144 Florence, Italy \\ ${ }^{6}$ Institute of Microbiology, University of Innsbruck, 6020 Innsbruck, Austria \\ ${ }^{7}$ Fondazione Edmund Mach, 38010 San Michele all'Adige, Italy
}

Correspondence to: Markus Egli (markus.egli@geo.uzh.ch)

Received: 13 July 2015 - Published in Biogeosciences Discuss.: 8 September 2015

Revised: 8 February 2016 - Accepted: 17 February 2016 - Published: 11 March 2016

\begin{abstract}
Due to the large size (e.g. sections of tree trunks) and highly heterogeneous spatial distribution of deadwood, the timescales involved in the coarse woody debris (CWD) decay of Picea abies (L.) Karst. and Larix decidua Mill. in Alpine forests are largely unknown. We investigated the CWD decay dynamics in an Alpine valley in Italy using the chronosequence approach and the five-decay class system that is based on a macromorphological assessment. For the decay classes 1-3, most of the dendrochronological samples were cross-dated to assess the time that had elapsed since tree death, but for decay classes 4 and 5 (poorly preserved tree rings) radiocarbon dating was used. In addition, density, cellulose, and lignin data were measured for the dated CWD. The decay rate constants for spruce and larch were estimated on the basis of the density loss using a single negative exponential model, a regression approach, and the stagebased matrix model. In the decay classes $1-3$, the ages of the CWD were similar and varied between 1 and 54 years for spruce and 3 and 40 years for larch, with no significant differences between the classes; classes 1-3 are therefore not indicative of deadwood age. This seems to be due to a time lag between the death of a standing tree and its contact with the soil. We found distinct tree-species-specific differences in decay classes 4 and 5, with larch CWD reaching an aver-
\end{abstract}

age age of 210 years in class 5 and spruce only 77 years. The mean CWD rate constants were estimated to be in the range 0.018 to $0.022 \mathrm{y}^{-1}$ for spruce and to about $0.012 \mathrm{y}^{-1}$ for larch. Snapshot sampling (chronosequences) may overestimate the age and mean residence time of CWD. No sampling bias was, however, detectable using the stage-based matrix model. Cellulose and lignin time trends could be derived on the basis of the ages of the CWD. The half-lives for cellulose were 21 years for spruce and 50 years for larch. The half-life of lignin is considerably higher and may be more than 100 years in larch CWD. Consequently, the decay of Picea abies and Larix decidua is very low. Several uncertainties, however, remain: ${ }^{14} \mathrm{C}$ dating of $\mathrm{CWD}$ from decay classes 4 and 5 and having a pre-bomb age is often difficult (large age range due to methodological constraints) and fall rates of both European larch and Norway spruce are missing.

\section{Introduction}

The quantity and residence time of deadwood or coarse woody debris in Alpine forests are crucial in assessing the carbon cycle to ensure sustainable management of forests. Coarse woody debris (CWD) is defined as large-sized dead- 
wood pieces, such as stems of dead trees lying on the forest floor, standing dead trees and stumps, big branches, and wood boles in all stages of decomposition. Deadwood plays an important role in maintaining biodiversity in forest ecosystems (Müller and Bütler, 2010) and storing carbon (Di Cosmo et al., 2013), as well as contributing to nutrient cycle processes (Palviainen et al., 2010). The amount of deadwood varies greatly from managed to natural forests. In managed European Alpine forests, for example, the average stock of deadwood is estimated to be about $26 \mathrm{~m}^{3} \mathrm{ha}^{-1}$, while in old growth Alpine coniferous forests it can be up to 150-190 $\mathrm{m}^{3} \mathrm{ha}^{-1}$ (Barbati et al., 2014). Residence time for deadwood (e.g. Krüger et al., 2014) - from the moment the tree reaches the forest floor until it loses $95 \%$ of the mass can range from decades to several hundred years, depending on intrinsic and external factors. These factors include the dimensions of the log, the wood chemistry, and the site conditions, in particular the mean annual temperature and soil moisture.

Various different sampling designs have been used in the past to determine the time since death to estimate the decay rate of deadwood. Long-term studies can provide reliable results (Müller-Using and Bartsch, 2009), but the slow decay dynamics of wood usually require a decadal observation period. Bond-Lamberty and Gower (2008) used the ratio of deadwood mass input into the pool of initial deadwood to estimate its decay rate based on a 7-year observation period. Such time sequences (chronosequence) offer ideal scenarios to study deadwood dynamics. If windthrow, fire regeneration, and harvest events are known, the starting point in the timeline of the decay process can be specified. However, the exact year of such events is often uncertain, which means precisely dating a tree's death is critical. Dendrochronology can be a helpful tool to determine the year of death, and the technique has been used in several studies to determine the time elapsed since tree death (Campbell and Laroque, 2007; Lombardi et al., 2008, 2013). Other researchers have used radiocarbon dating to date the last recognisable ring of deadwood. For example, Kueppers et al. (2004) estimated the turnover time of lodgepole pine along a subalpine elevation gradient and Krüger et al. (2014) compared tree-ring cross-dating and radiocarbon dating, demonstrating that the two techniques produce comparable results. The decay rate can be estimated by relating the time since death to the density loss or mass loss of deadwood during a given time period (e.g. Busse, 1994; Melin et al., 2009). The decay rate is commonly expressed through a decay constant $k$, which indicates the density loss or mass loss per year. This constant is derived from a decay model (Harmon et al., 1986), which can be most simply expressed by the equation

$x_{t}=x_{0} e^{-k t}$

(single-negative-exponential model), where $x_{t}$ is the density or mass of deadwood at a given time and $x_{0}$ is the initial density or mass (Jenny et al., 1949; Olson, 1963). Other decay models have also been developed that take wood decomposition into account (reviewed by Mackensen et al., 2003). Several authors (Minderman, 1968; Wider and Lang, 1982; Means et al., 1985) consider the different wood components, e.g. bark, sapwood, heartwood, and chemical compounds, and combine them in multiple-exponential equations. Other authors (e.g. Harmon et al., 1986) consider the time elapsed from the death of a standing tree to the moment when it falls and comes in contact with the forest floor (lag-time models). In several environments, e.g. on dry mountain slopes, the time lag between death and contact with the forest floor can last for almost the entire decay process (Kueppers et al., 2004). A few models take not only the losses due to heterotrophic respiration and leaching into account but also losses due to fragmentation (Mackensen et al., 2003).

One of the most important components of deadwood is coarse woody debris. Because the spatial distribution of CWD is highly heterogeneous, only few quantitative data about its long-term decay dynamics are available for European Alpine forests. Decay models in Europe have, therefore, rarely been parameterised using empirically derived decay constants. In the field, the different stages of CWD decomposition are often described by so-called decay classes (as defined by Hunter, 1990) through a visual assessment of the wood status (Lombardi et al., 2013). In a previous study, Petrillo et al. (2015) demonstrated that the Hunter classification is particularly suitable for describing changes in the physical-chemical characteristics of European larch (Larix decidua Mill.) and Norway spruce (Picea abies (L.) Karst.) deadwood in alpine environments. The physical-chemical properties of deadwood changed distinctly during decay and correlated well with the five decay classes. Furthermore, no substantial differences between spruce and larch decay patterns were found, although the wood chemistry of the living trees differed slightly between these two species (significant differences were found in the cellulose content, with $45.1 \%$ for spruce and $39.4 \%$ for larch; these differences were, however, already negligible in decay class 1 ; Petrillo et al., 2015). European larch and spruce are widespread in the Alps. Although C stocks in soils are substantial (e.g. Johnston et al., 2004), CWD is a non-negligible $C$ reservoir in subalpine forests (Sandström et al., 2007). Consequently, it is thus very important to know which timescales are involved in CWD decay. Jebrane et al. (2014) showed that Scots pine is more decay resistant than European larch, which suggests that the decay rate of pine is lower. Some species of larch are, however, considered economically valuable due to their hard, heavy, and decay-resistant wood (Parker, 1993), which implies that residence time of larch CWD should be longer.

The aim of our work was to find out (i) which timescales are involved in CWD decay of $P$. abies and $L$. decidua in the Alps and (ii) how these timescales correlate with the fivedecay class system. We hypothesised that the CWD decay of these coniferous trees is relatively slow (due to, for exam- 


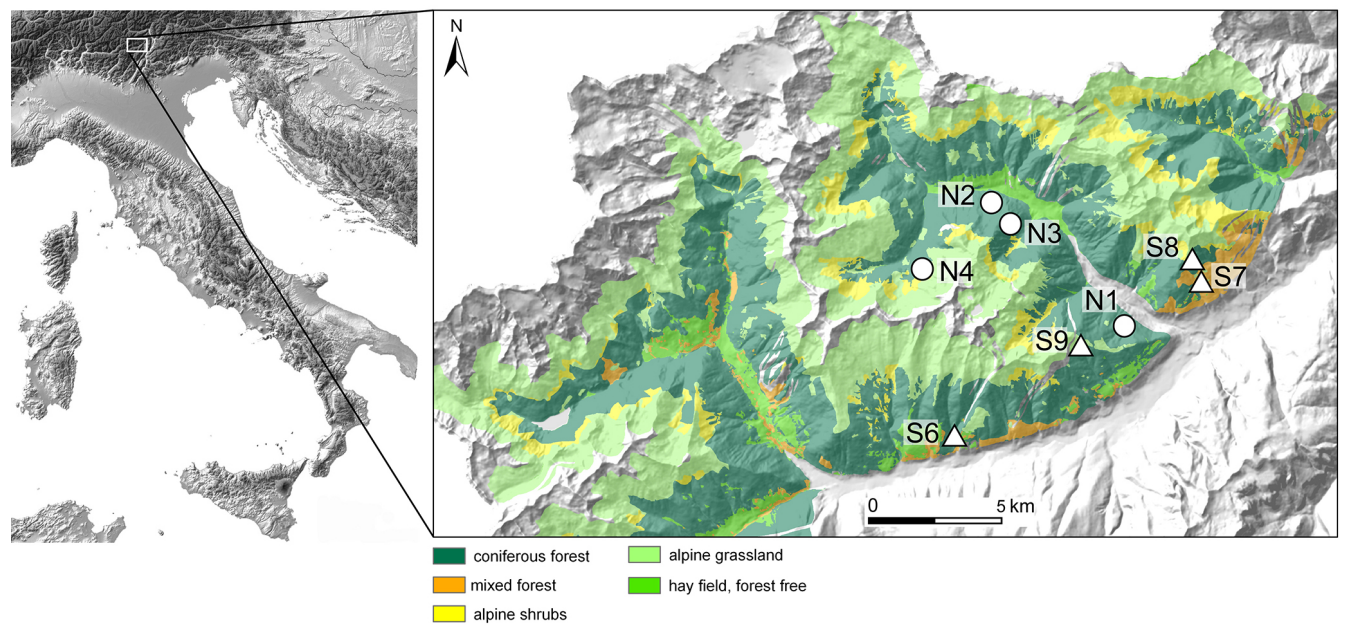

Figure 1. Location of the study area with the major vegetation units and investigation sites. Data source: Museo delle Scienze (Trento), CORINE Landcover (Joint Research Centre of the European Union), and scilands GmbH. The site label N indicates north-facing sites and S south-facing sites.

ple, the nutrient availability for macro- and microorganisms being unfavourable).

\section{Materials and methods}

\subsection{Site description}

The study area is located in the north-eastern Italian Alps, in Val di Sole and Val di Rabbi (Fig. 1; Table 1). The climate of the valleys ranges from temperate to alpine (above the timberline), the mean annual temperature from $8.2^{\circ} \mathrm{C}$ at the valley floor to about $0^{\circ} \mathrm{C}$ at $2400 \mathrm{~m}$ a.s.l., and the mean annual precipitation from approximately 800 to $1300 \mathrm{~mm}$ (Sboarina and Cescatti, 2004). The geological substrate is paragneiss debris in all sites. The soil units are Cambisols, Umbrisols, and Podzols. The soil properties at each site could be taken from a previous study (Egli et al., 2006). The timberline is close to 2000-2200 m a.s.l., with the forests dominated by Norway spruce and, at the highest altitudes, European larch.

\subsection{Sampling protocol}

Norway spruce and European larch CWD was sampled at eight sites ranging in altitude from 1200 to $2000 \mathrm{~m}$ a.s.l. In spring and summer 2013, wood cores from living trees and cross sections of CWD were taken from all sites. At each site, five or six living trees were sampled in two directions per each tree at $130 \mathrm{~cm}$ height (breast height) using an incremental corer $(0.5 \mathrm{~cm}$ in diameter; Suunto, Finland). The wood cores were wrapped in paper and transported to the laboratory, where they were air-dried, fixed onto a flat wooden support, and sanded in order to obtain a smooth surface for tree-ring measurements. Before sampling, each CWD was first classified relative to the decay stage. The classification was done in situ using the five-class classification system of Hunter (1990) (Table 2), which is based on visual, geometric, and tactile features and considers the presence/absence of twigs and bark, the shape of the log section, and the deadwood structure. To sample CWD, a circular area of $50 \mathrm{~m}$ radius was explored at each plot. In total, $177 \mathrm{CWD}$ samples were collected (46 of them were dated). At the highest sites, the forests consisted predominantly of larch trees. In addition, one lower site on the south-facing slope (S7) also had a predominantly larch forest. All other sites are spruce-dominated. Samples were taken randomly either using a manual saw or, in more advanced stages of decay, simply by hand. If necessary, they were wrapped up with tape to preserve their structure during transport to the laboratory, where they were air-dried and sanded. For CWD in more advanced decay stages (decay classes 4 and 5), a $25 \mathrm{~cm} \times 30 \mathrm{~cm}$ bag was filled. The samples were then oven-dried at $50^{\circ} \mathrm{C}$, but not sanded. To establish a master chronology, 83 wood cores were taken from living trees, 29 from larch, and 54 from spruce. Two cores were taken from each tree. In three cases, one of the two cores taken from the same tree was too damaged to be measured (one at $\mathrm{N} 02$, one at S06, and one at S07). Furthermore, two outliers were excluded from the master chronology, namely one measured core at S07 and one at S08. CWD was dated using 46 cross sections from deadwood (18 from larch and 28 from spruce).

\subsection{Dendrochronological dating}

At each site, the 10 or 12 wood cores taken from living trees were used to build a reference (master) ring-width chronology for each species. Tree rings were first counted and then measured using the LINTAB tree-ring-width measurement device (RINNTECH e.K., Heidelberg, Germany), coupled 


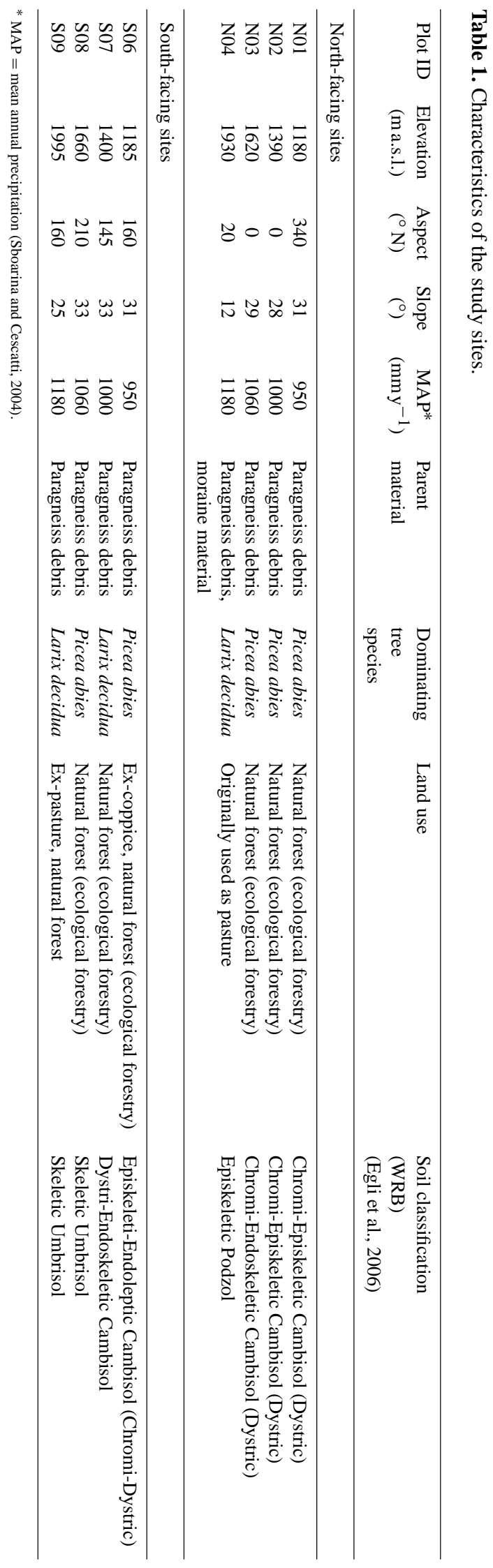

together with a stereomicroscope (Leica, Germany). The two ring-width measurements from the same tree were first crosschecked and then incorporated into a single average master chronology for each species and for each site. To maximise the common signal, one outlier per species was excluded from the relative master chronology. These two tree-ring measurements exhibited a poor correlation with the other, probably due to an elevated number of missing rings. The statistical software TSAP-Win ${ }^{\mathrm{TM}}$ (Time Series Analysis Program, RINNTECH e.K., Heidelberg, Germany) was used to calculate the Gleichläufigkeit, GLK (Kaennel and Schweingruber, 1995), i.e. the agreement between two ring-width series. The correlations among all the ring-width series of living trees and CWD were statistically assessed using the software COFECHA (Holmes et al., 1986). EPS (expressed population signal; Wigley et al., 1984) was calculated using the statistic software R.

The deadwood cross sections were measured from the most external ring to the pith, along three or four different radial directions. The individual CWD series (i.e. floating chronologies) were matched to the master chronology of the corresponding species. We visually and statistically checked the deadwood series using the GLK to obtain the highest value with the master chronology and to date the year of death of the tree from which the deadwood originated.

\subsection{Radiocarbon dating}

The CWD of the decay classes 4 and 5 was too degraded to be dated through tree-ring analysis as their wood structure was too altered and the tree rings were no longer visible. In such cases, the outermost part of the CWD was sampled and ${ }^{14} \mathrm{C}$-dated (Fig. 2a, b). We selected a small fragment of $1-$ $2 \mathrm{~cm}^{3}$ in volume from the outermost part assumed to have contained the last tree rings produced before the tree died (Fig. 2c, d). This small fragment was gently cleaned with a brush to remove any non-woody elements, such as particles of soil or vegetation like moss.

The organic samples were cleaned using an acid-alkaliacid (AAA) treatment. The samples were then heated under vacuum in quartz tubes with $\mathrm{CuO}$ (oxygen source) to remove any absorbed $\mathrm{CO}_{2}$ in the $\mathrm{CuO}$. The tubes were evacuated, sealed, and heated in the oven at $900{ }^{\circ} \mathrm{C}$ to obtain $\mathrm{CO}_{2}$. The $\mathrm{CO}_{2}$ of the combusted sample was mixed with $\mathrm{H}_{2}(1: 2.5)$ and catalytically reduced over iron powder at $535^{\circ} \mathrm{C}$ to elemental carbon (graphite). After reduction, the mixture was pressed into a target so that carbon ratios could be measured by accelerator mass spectrometry (AMS) using the $0.2 \mathrm{MV}$ radiocarbon dating facility (MICADAS) of the Laboratory of Ion Beam Physics at the Swiss Federal Institute of Technology of Zurich (ETHZ).

The calendar ages were obtained using the OxCal 4.2 calibration program (Bronk Ramsey, 2001, 2009) based on the IntCal 13 calibration curve, and for modern samples the bomb 13NH1 curve (Reimer et al., 2013; Hua et al., 2013) 
Table 2. The five decay-class system of log decomposition (according to Hunter, 1990).

\begin{tabular}{|c|c|c|c|c|c|}
\hline \multirow[t]{2}{*}{ Log features } & \multicolumn{5}{|c|}{ Decay classes } \\
\hline & 1 & 2 & 3 & 4 & 5 \\
\hline Bark & Intact & Partially absent & Absent & Absent & Absent \\
\hline Twigs & Present & $\begin{array}{l}\text { Partially absent } \\
\text { or absent }\end{array}$ & Absent & Absent & Absent \\
\hline $\begin{array}{l}\text { Shape of radial } \\
\text { section }\end{array}$ & Round & Round & Round & Oval & Very oval \\
\hline Colour & Original & Original & $\begin{array}{l}\text { Faded in the } \\
\text { external part }\end{array}$ & $\begin{array}{l}\text { Reddish brown } \\
\text { or faded }\end{array}$ & Reddish or faded \\
\hline Texture of wood & Intact & Intact & $\begin{array}{l}\text { Soft outer layer, } \\
\text { intact inner part }\end{array}$ & Small pieces, soft & $\begin{array}{l}\text { Powdery or fibrous, } \\
\text { very soft }\end{array}$ \\
\hline Contact with soil & $\begin{array}{l}\text { Log elevated on } \\
\text { what remains } \\
\text { of branches }\end{array}$ & $\begin{array}{l}\text { Log in contact } \\
\text { with soil }\end{array}$ & $\begin{array}{l}\text { Log in contact } \\
\text { with soil }\end{array}$ & $\begin{array}{l}\text { Log in contact } \\
\text { with soil }\end{array}$ & $\begin{array}{l}\text { Log in contact } \\
\text { with soil and } \\
\text { partially buried }\end{array}$ \\
\hline
\end{tabular}
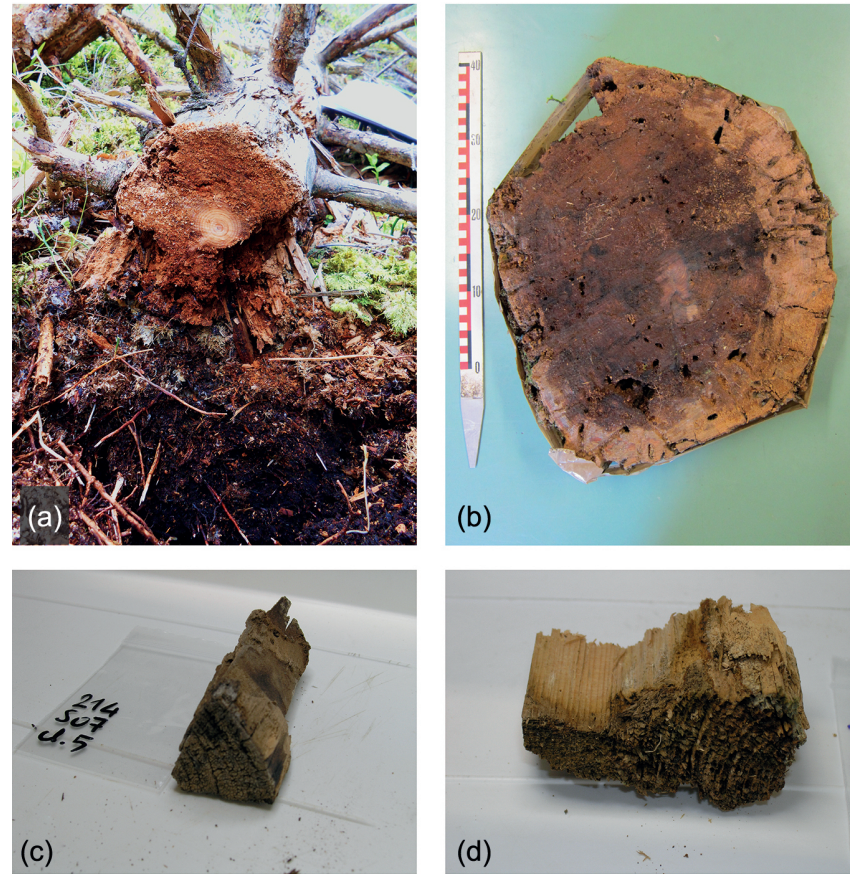

Figure 2. Cross section of (a) spruce deadwood in the field (site N03) and (b) larch deadwood (site S07). Examples (c and d) of deadwood fragments classified as decay class 4 dated using radiocarbon (outermost part of the wood piece).

was used. Several samples (before AD 1950) had a widely calibrated age range. For these samples, we used the age range with the highest probability of confining the time elapsed since death very strictly.

\subsection{Determining the cellulose and lignin}

To obtain $\alpha$ cellulose (Boettger et al., 2007), $10 \mathrm{mg}$ of powdered wood was weighed in Teflon bags for chemical and thermal treatments. All wood (sapwood and heartwood) was homogenised prior to chemical analysis. We decided to use this procedure, because it was not possible to distinguish between sapwood and heartwood for the most decayed stages. Samples were first washed in a $5 \% \mathrm{NaOH}$ solution at $60^{\circ} \mathrm{C}$ for $2 \mathrm{~h}$ and then for an additional $2 \mathrm{~h}$ with fresh $5 \% \mathrm{NaOH}$ solution (the $\mathrm{NaOH}$ solution was discarded each time), before finally being rinsed three times using boiling distilled water (see also Petrillo et al., 2015). The samples were then washed in a $7 \% \mathrm{NaClO}_{2}$ solution at $60^{\circ} \mathrm{C}$ for $30 \mathrm{~h}$, changing the solution at least every $10 \mathrm{~h}$ and then rinsed three times with boiling distilled water. The pockets were dried in the oven at $50^{\circ} \mathrm{C}$ and the cellulose content was determined as the difference between the initial weight and dried samples. The so-called Klason lignin (lignin insoluble in strong acid; Dence and Lin, 1992) was determined gravimetrically after a sequential extraction in which $0.2 \mathrm{~g}$ of each sample was washed three times with $5 \mathrm{~mL}$ of distilled water at $80^{\circ} \mathrm{C}$. After each washing, the samples were centrifuged for $10 \mathrm{~min}$ at $4500 \mathrm{rpm}$, dried in the oven at $80^{\circ} \mathrm{C}$, and washed three times with $5 \mathrm{~mL}$ of ethanol. They were then centrifuged again (10 min at $4500 \mathrm{rpm})$ and the supernatant was discarded. After being dried at $60^{\circ} \mathrm{C}$ in the oven, $60 \mathrm{mg}$ of each sample was treated with $0.6 \mathrm{~mL}$ of $72 \% \mathrm{H}_{2} \mathrm{SO}_{4}$ in a warm $\left(30^{\circ} \mathrm{C}\right)$ bath for $1 \mathrm{~h}$, and then, after adding $16.8 \mathrm{~mL}$ of distilled water, in an autoclave at $120^{\circ} \mathrm{C}$ for $1 \mathrm{~h}$. Subsequently, the samples were filtered and the filtrate used to determine of the acidsoluble lignin. The insoluble lignin was dried in the oven at $105^{\circ} \mathrm{C}$ and determined as the difference between the dry and initial weight. 
In total, the cellulose and lignin content was measured for 177 CWD samples.

\subsection{Estimating decomposition rate constants on the basis of density loss}

In a previous investigation (Petrillo et al., 2015), the density of the deadwood samples was measured. To estimate the decay constants, the average densities in class 1 and class 5 (the earliest and latest decay stages) were used and the singlenegative exponential model of Jenny et al. (1949) applied (see Eq. 1). Equation (1) was then solved for the decay constant $k$ according to Eq. (2):

$k=\frac{-\ln \left(x_{t} / x_{0}\right)}{t}$,

where $x_{t}$ is the density of each deadwood sample at a given time (i.e. the estimated time elapsed since death), and $x_{0}$ the initial density $\left(0.45 \mathrm{~g} \mathrm{~cm}^{-3}\right.$ for Picea abies and $0.59 \mathrm{~g} \mathrm{~cm}^{-3}$ for Larix decidua).

The density of all CWD samples was then compared to the related ages to derive the overall decomposition rates. A similar procedure was applied to cellulose and lignin to derive compound-specific decomposition rates of CWD.

Calculating mean residence time in decay classes from a single time point sample, rather than using longitudinal long-term data, tends to overestimate residence time due to a higher probability of inclusion of slow-decaying trees (Kruys et al., 2002). Consequently, snapshot sampling may overestimate the age and mean residence time of CWD. Thus, the decay rate could be underestimated. Calculating the overall CWD decay rates by using density values along a chronosequence risks, therefore, that a certain amount of error is introduced. This bias can be corrected using the proposed approach of Kruys et al. (2002). The mean residence time of CWD in a particular decay class is

$E_{m}=\frac{\sum_{i=1}^{N} b_{m_{i}}}{N}$,

where $b_{m_{i}}$ is the residence time of tree $i$ in a specific decay class $m$ and $N$ are trees present during the time period. The estimator of $E_{m}$ is

$\hat{E}_{m}=\frac{\sum_{i=1}^{n_{m}} \frac{b_{m_{i}}}{\mathrm{cb}_{m_{i}} / T}}{\sum_{i=1}^{n_{\text {tot }}} \frac{1}{\mathrm{cl}_{i} / T}}=\frac{n_{m}}{\sum_{i=1}^{n_{\text {tot }}} \frac{1}{l_{i}}}$

where $c$ is the proportion of the logs existing at time point $t, n_{m}$ is the number of trees from which samples were taken in decay class $m, n_{\text {tot }}$ is the total number of sampled trees, and $l_{i}$ is the total residence time of each tree across all decay classes. The expressions $\mathrm{cb}_{m_{i}} / T$ and $\mathrm{cl}_{i} / T$ are the probabilities of including units $b_{m_{i}}$ and $l_{i}$ in the sample, respectively.

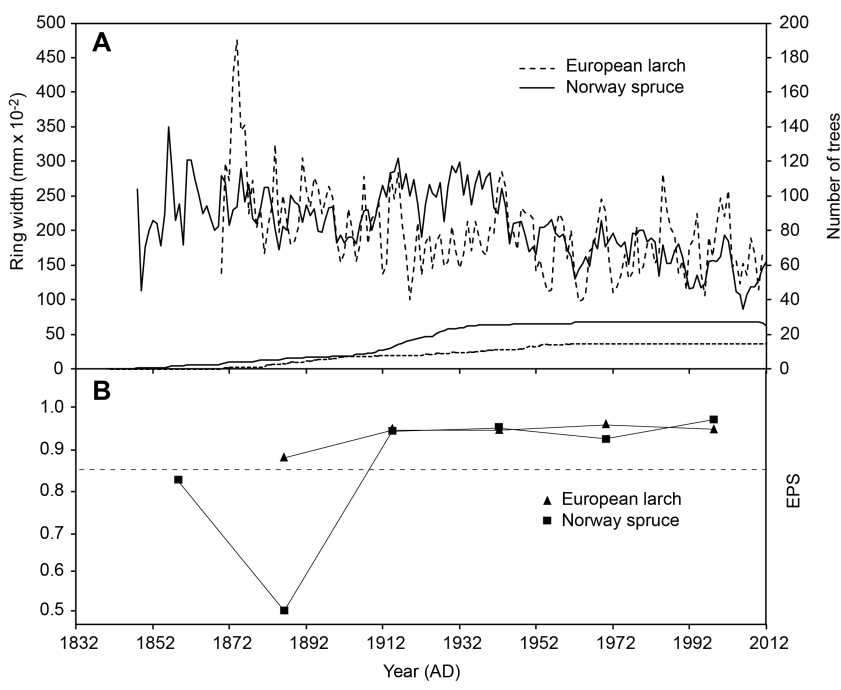

Figure 3. Master chronologies for spruce and larch to cross-date the deadwood (a) and the expressed population signal (EPS) for segments of constant periods (b). A noise-free chronology is achieved with an EPS > 0.85 (dashed line; Wigley et al., 1984)

According to Kruys et al. (2002) it was assumed that all wood samples were taken half-way through their residence time in that class. The parameter $l_{i}$ was calculated as age $i / x ;$ age $_{i}$ is the measured time since death of tree $i$ and

$x=\frac{r_{m}}{2}+\sum_{k=1}^{m-1} r_{k}$,

where $x$ is the sum of proportions, $r_{k}$, assigned to classes preceding the class of tree $i+50 \%$ of the proportion assigned to tree $i$ 's class, $r_{m}$. $\hat{E}_{m}$ can be calculated iteratively for the different classes. Convergence occurred after 5-10 iterations.

\section{Results}

\subsection{Living chronologies}

Two master chronologies for spruce and larch were obtained extending over 164 and 141 years, respectively (Fig. 3). The spruce chronology ranged from AD 1848 to 2012 (Fig. 3) and the larch chronology from AD 1871 to 2012. The tree-ring widths of the same species correlated well among each other with a high GLK. When considering each individual plot, the GLK values were highest at S09 (larch), with a mean GLK of $0.70( \pm 0.1)$ and lowest at N01 (spruce) with a mean GLK of $0.58( \pm 0.13)$. The series inter-correlation coefficients obtained using COFECHA were 0.535 for spruce and 0.641 for larch (Pearson correlation; all series above 0.3281 were significant; $99 \%$ confidence interval). The EPS values (Fig. 3b) were in most cases above (or close to) 0.85 (a threshold value for noise-free chronology; Wigley et al., 1984), except for Picea abies for the period of AD 1870-1910. Spruce 
Table 3. Typical properties and ages of Norway spruce and European larch CWD in classes 1-3. Ages were obtained mostly from dendrochronological measurements and a few (marked with asterisks) from ${ }^{14} \mathrm{C}$ dating (for details of ${ }^{14} \mathrm{C}$ dating see Appendix $\mathrm{A}$ ).

\begin{tabular}{llcccccc}
\hline Plot & Tree species & $\begin{array}{c}\text { Decay } \\
\text { class }\end{array}$ & $\begin{array}{c}\text { Density } \\
\left(\mathrm{g} \mathrm{cm}^{-3}\right)\end{array}$ & $\begin{array}{c}\text { Cellulose } \\
(\%)\end{array}$ & $\begin{array}{c}\text { Lignin } \\
(\%)\end{array}$ & $\begin{array}{c}\text { Year of } \\
\text { death }\end{array}$ & $\begin{array}{c}\text { CWD } \\
\text { age }\end{array}$ \\
\hline N03 & Norway spruce & 1 & 0.32 & 34.8 & 22.4 & 2009 & 4 \\
S08 & Norway spruce & 1 & 0.40 & 31.3 & 33.2 & 1992 & 21 \\
N01 & Norway spruce & 1 & 0.45 & 43.4 & 22.0 & 1988 & 25 \\
N02 & Norway spruce & 1 & 0.44 & 41.4 & 23.3 & 1969 & 44 \\
N03 & Norway spruce & 2 & 0.39 & 41.4 & 35.9 & 2006 & 7 \\
N03 & Norway spruce & 2 & 0.44 & 28.4 & 25.0 & 2004 & 9 \\
N03 & Norway spruce & 2 & 0.39 & 27.8 & 25.9 & 2004 & 9 \\
S08 & Norway spruce & 2 & 0.36 & 38.2 & 23.1 & 2003 & 10 \\
N02 & Norway spruce & 2 & 0.11 & 39.2 & 14.2 & 1996 & 17 \\
N03 & Norway spruce & 2 & 0.43 & 40.8 & 21.5 & 1993 & 20 \\
N01 & Norway spruce & 2 & 0.39 & 28.2 & 24.3 & 1970 & 43 \\
N02 & Norway spruce & 2 & 0.67 & 27.8 & 25.9 & 1959 & 54 \\
N03 & Norway spruce & 3 & 0.48 & 43.6 & 23.4 & 2012 & 1 \\
N03 & Norway spruce & 3 & 0.38 & 36.6 & 24.2 & 2005 & 8 \\
N03 & Norway spruce & 3 & 0.39 & 37.4 & 10.7 & 2005 & 8 \\
N01 & Norway spruce & 3 & 0.30 & 22.3 & 35.1 & 1979 & 34 \\
N02 & Norway spruce & 3 & 0.48 & 33.5 & 24.6 & 1970 & 43 \\
S09 & European larch & 1 & 0.60 & 37.2 & 21.1 & 2010 & 3 \\
N04 & European larch & 1 & 0.59 & 44.2 & 16.9 & 1973 & 40 \\
S07* & European larch & 1 & 0.31 & 21.2 & 39.6 & 2007 & 6 \\
S07 & European larch & 2 & 0.58 & 20.2 & 38.0 & 2010 & 3 \\
S09 & European larch & 2 & 0.53 & 37.3 & 31.0 & 2000 & 13 \\
S07* & European larch & 2 & 0.30 & 30.4 & 40.6 & 2003 & 10 \\
S07* & European larch & 3 & 0.27 & 6.7 & 63.0 & 2004 & 9 \\
S09* & European larch & 3 & 0.60 & 4.2 & 40.8 & 1973 & 40 \\
S09* & European larch & 3 & 0.33 & 23.3 & 58.4 & 1968 & 45 \\
\hline
\end{tabular}

and larch, however, had quite different growth patterns, with a Pearson correlation coefficient of 0.274 when comparing the two species-specific master chronologies. The spruce chronology indicated that the trees grew homogeneously throughout the whole observation period, while larch seemed to be more sensitive to climate with marked high and low growth periods (positive and negative pointer years, Fig. 3). Furthermore, the negative and positive pointer years were not synchronous in the larch and spruce master chronologies. Even though more larch trees were sampled at southfacing sites and at higher elevation, we can exclude a bias due to an unbalanced sample distribution. Within the same homogenous climatic region, similar growth patterns are found (Carrer and Urbinati, 2006). The differences between the two master chronologies are rather influenced by the different phenology of the two species. Larch is a deciduous tree with a deep root system, while spruce is evergreen and has a shallow root system. Furthermore, the larch master chronology is cyclically influenced by outbreaks of the larch bud defoliator Zeiraphera diniana $\mathrm{Gn}$. that result in the abrupt occurrence of extremely narrow tree rings, which are not observed for spruce (Esper et al., 2007). The growth pattern of some trees, however, differed considerably from that of the master chronology, possibly due to the specific growth conditions of the individual trees, e.g. if their growth was very suppressed because of competition. Such outliers were excluded from the chronologies.

\subsection{Age of coarse woody debris (CWD)}

Most of the samples of the decay classes 1-3 could be dendrochronologically dated, but those of decay classes 4 and 5 had to be radiocarbon-dated because of the poorly preserved tree rings (Tables 3,4). In the first three decay classes, the CWD ages of spruce and larch seem to be in a similar range. The values vary from 1 to 54 years. Interestingly, the average age of CWD does not seem to increase from class 1 to 3 . The average age was around 10-20 years for all decay classes assuming a relatively fast decay. In decay classes 4 and 5, the average and maximum ages of CWD were usually higher for larch than for spruce. In decay class 4 , spruce CWD has an average of about 42 years (median 43 years; Fig. 4) and larch CWD an average of 87 years (median 45 years). In decay class 5, the average age of spruce CWD increases to 77 years and the age of larch CWD to 210 years. This shows that larch wood, particularly in the decay classes 4 and 5, is much more 


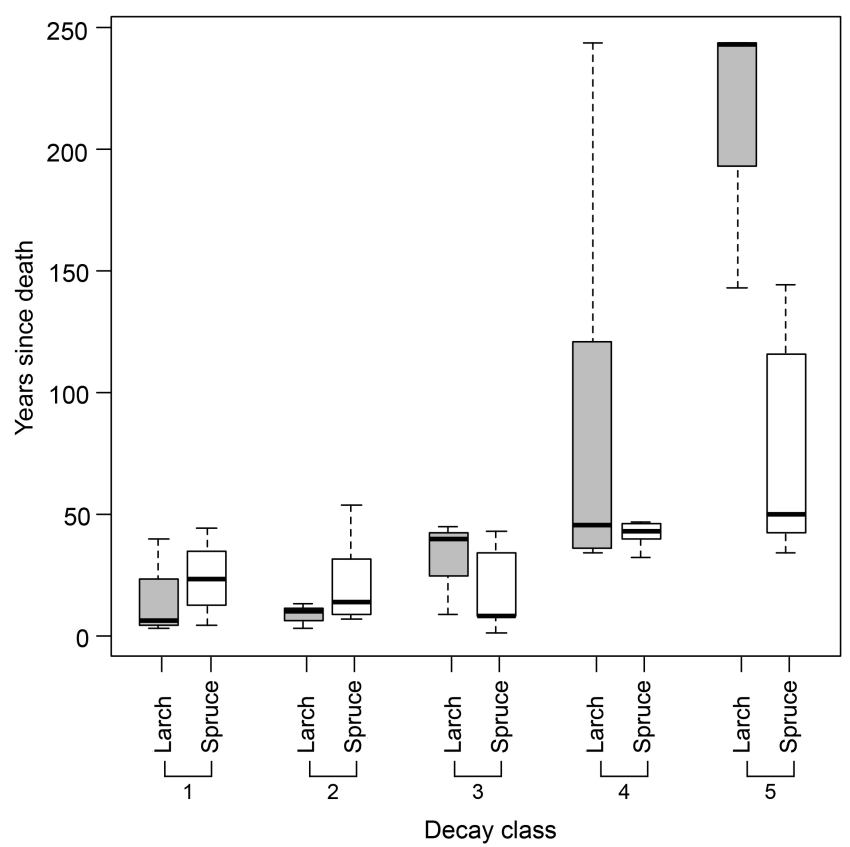

Figure 4. Box plots of the larch and spruce deadwood age as a function of decay class.

resistant to rotting than spruce. Several CWDs had an age of around 200 years. The calibration of radiocarbon dates for such ages is, however, complicated by the so-called plateaus that give rise to a relatively wide range of calibrated ages. To minimise the array of possibilities, we used the age range with the highest probability for confining the time elapsed since death more strictly.

\subsection{Relations between year since death, decay class, and physical-chemical properties of deadwood}

The physical-chemical data for the CWD $(n=177)$ are given in Petrillo et al. (2015) and Tables 3 and 4 so that the density and the cellulose and lignin contents could be plotted as a function of the decay class and age of the CWD (Fig. 5). Since the relationship between the age of the CWD and physical-chemical characteristics was rather stochastic for the decay classes $1-3$, they were grouped and their average was used for further analysis. The decrease in density and cellulose concentrations and the simultaneous increase in lignin definitely proceed faster for the spruce CWD than for the larch CWD (Fig. 5). An exponential function best describes the trends in the cellulose and lignin concentrations with time.

The stage-based matrix model of Kruys et al. (2002) was applied to calculate the $k$ values (Table 5) as a function of tree species and decay stage (summed decay classes). Using the classical chronosequence approach, the decay rate constants per year $\left(\mathrm{y}^{-1}\right)$ were, furthermore, calculated for each dated sample based on the density loss of spruce and

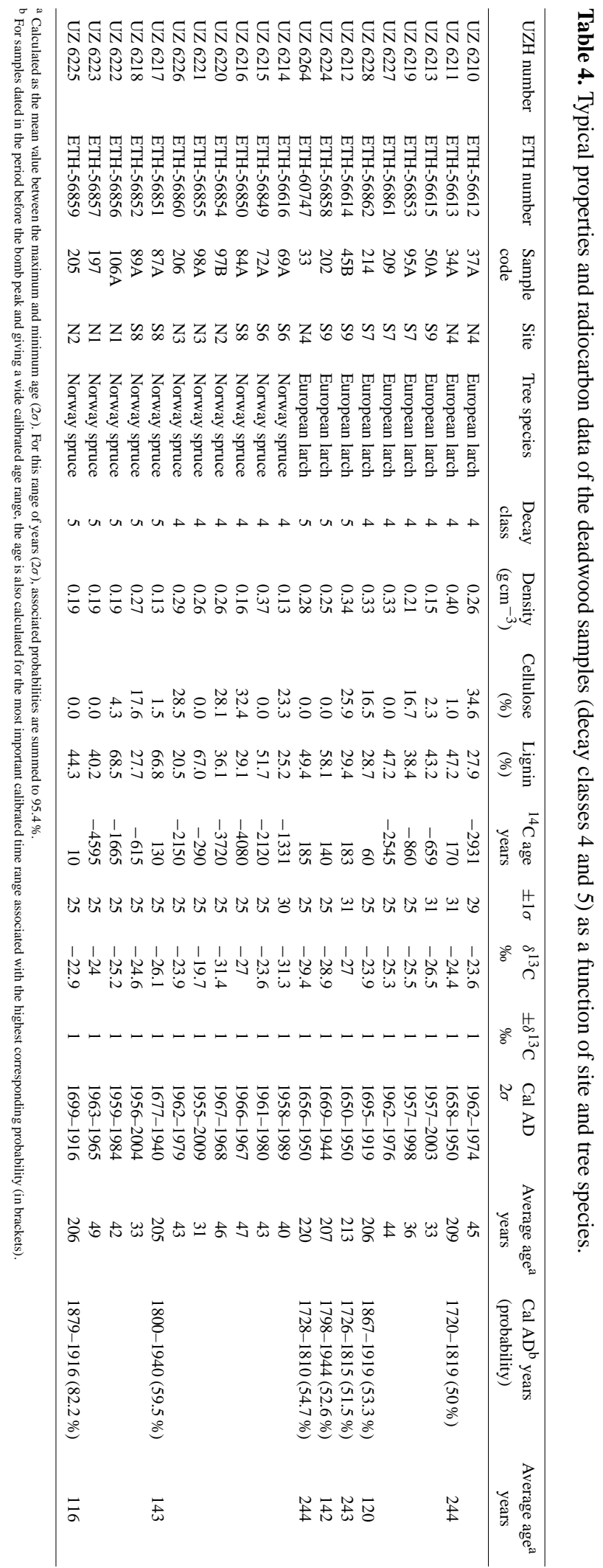



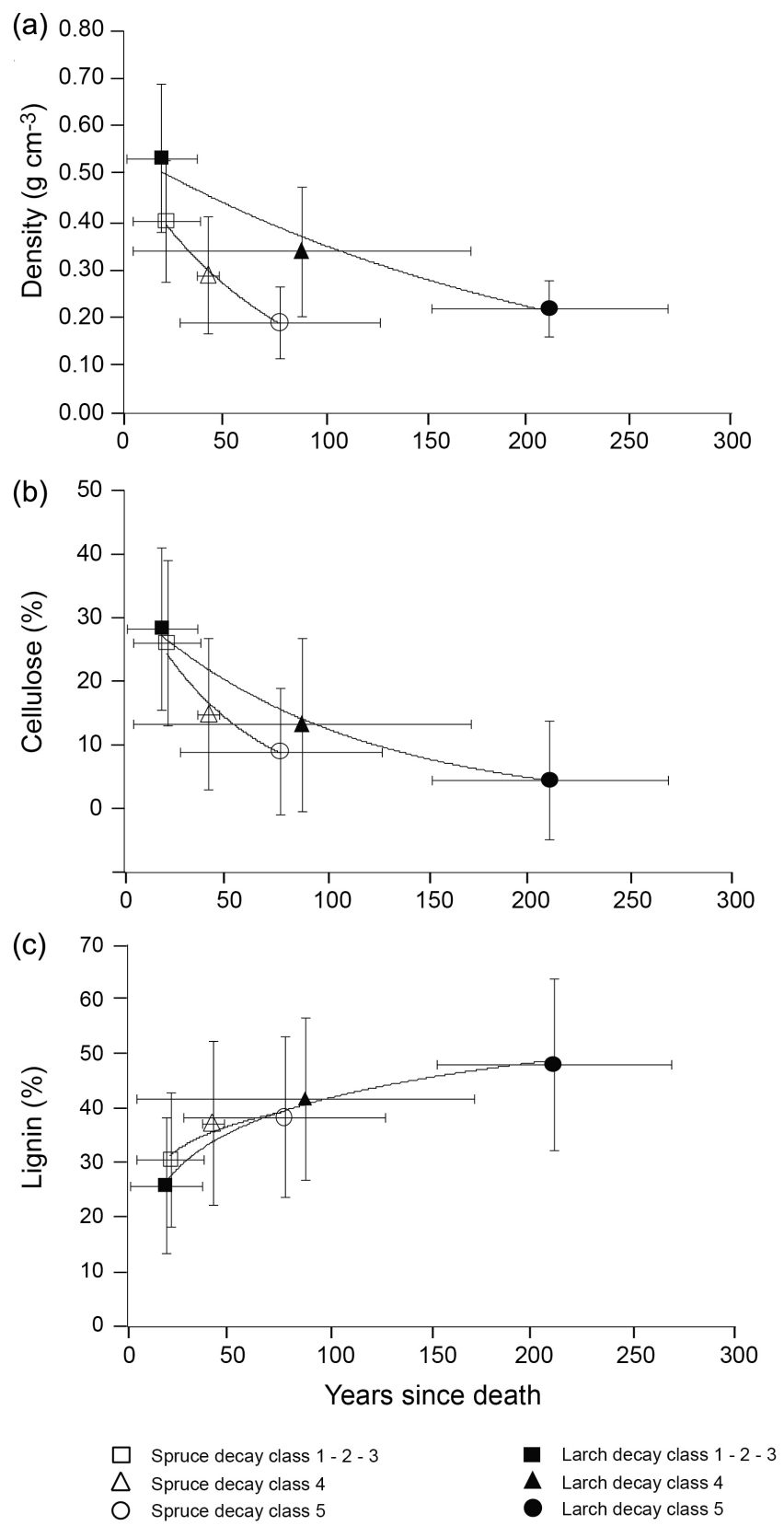

Figure 5. Relation between the age of spruce and larch CWD and density (a), cellulose \% (b), and lignin \% (c). The decay classes 1-3 were grouped together due to their similar age (Fig. 4).

larch CWD (Table 6). For spruce, we obtained an average value of $0.018\left(\mathrm{y}^{-1}\right)$ and for larch $0.012\left(\mathrm{y}^{-1}\right.$; Table 6$)$. The $k$ values were non-normally distributed. Using the KruskalWallis statistical test, we assessed the effects of the factors elevation, exposition, MAT (mean annual temperature), MAP (mean annual precipitation), species, and decay class on the $k$ values. None of these parameters significantly influenced the decay rate constant. Nonetheless, the range of $k$ values on south-facing plots seems to be slightly higher than those

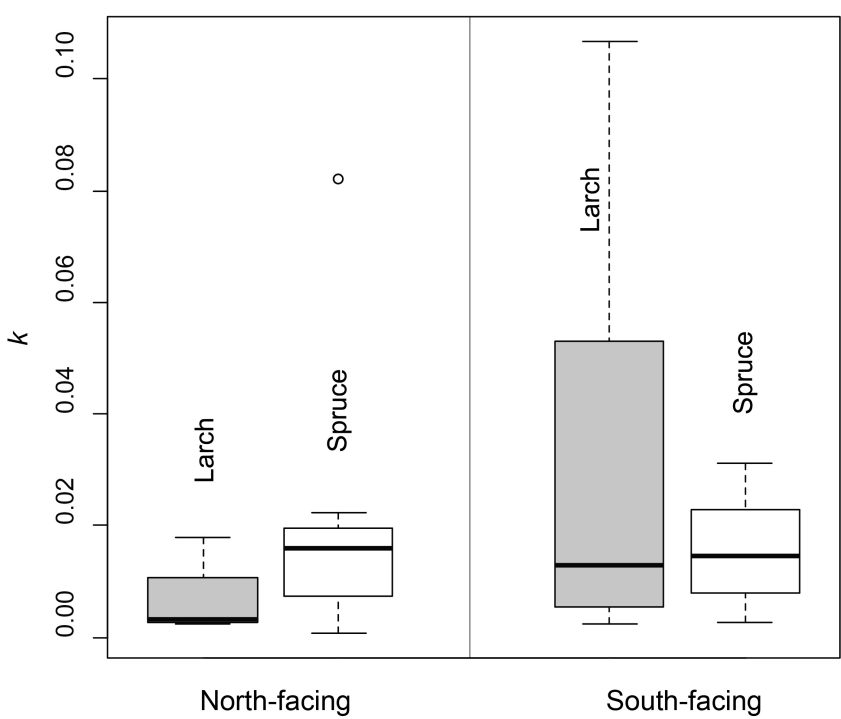

Figure 6. Calculated decay rate constants $(k)$ as a function of tree species and site exposure.

on the north-facing plots, which suggests the decomposition rates are faster on south-exposed slopes (Fig. 6). In addition, the $k$ values were estimated by comparing the CWD density with their age and by plotting an exponential regression curve (not shown). This approach resulted in lower $k$ values: $0.012 \mathrm{y}^{-1}$ for spruce and $0.005 \mathrm{y}^{-1}$ for larch. The mean residence time and half-lives are summarised in Table 7. The differences in mean residence time and rate constants between the model of Kruys et al. (2002) and the more classical approach (chronosequence) using Eq. (1) are small (Table 6). The Kruys et al. model gave slightly higher decay constants for Norway spruces $\left(0.022 \mathrm{y}^{-1}\right)$ and the same values $\left(0.018 \mathrm{y}^{-1}\right)$ for European larch (variant a) in Table 6.

\section{Discussion}

Although the five-decay class system is well suited to describe changes in the physical and chemical properties of deadwood (Lombardi et al., 2008), no real differences in the age of the CWD classes 1-3 could be found. The CWD in decay class 4 and 5 was, however, clearly older. This implies that the first three decay classes are not clearly related to deadwood age. Similarly, Lombardi et al. (2013) found no relationship between the age of CWD and the chemical properties of decay classes $1-3$. The main explanation for this unexpected finding is that there is probably a time lag between the death of a standing tree and its contact with the soil (Kueppers et al., 2004; Zielonka, 2006; Lombardi et al., 2013). Standing dead trees, i.e. snags, can remain upright for several years and decay much more slowly than fallen dead trees (Yatskov et al., 2003). Such an effect overshadows a clear age trend in decay. If the species-specific fall rates 
Table 5. Mean residence time and decay constants calculated using the stage-based matrix model of Kruys et al. (2002).

\begin{tabular}{|c|c|c|c|c|c|c|}
\hline \multirow[t]{2}{*}{ Decay class } & \multicolumn{2}{|c|}{ No. of samples } & \multicolumn{2}{|c|}{ Mean residence time } & \multicolumn{2}{|c|}{ Decay constant $\left(\mathrm{y}^{-1}\right)$} \\
\hline & Spruce & Larch & Spruce & Larch & Spruce & Larch \\
\hline 1 & 4 & 3 & 77 & 80 & 0.013 & 0.012 \\
\hline $1+2$ & 8 & 3 & 36 & 47 & 0.027 & 0.021 \\
\hline $1+2+3$ & 4 & 3 & 28 & 67 & 0.036 & 0.015 \\
\hline $1+2+3+4$ & 6 & 6 & 63 & 116 & 0.016 & 0.009 \\
\hline $1+2+3+4+5$ & 5 & 3 & 63 & 254 & 0.016 & 0.004 \\
\hline
\end{tabular}

Table 6. CWD decay parameters based on (a) Eq. (1), (b) the regression approach, and (c) stage-based matrix model of Kruys et al. (2002).

\begin{tabular}{ccccc}
\hline & & $\begin{array}{c}\text { Average decay } \\
\text { constant } k \\
\left(\mathrm{y}^{-1}\right)\end{array}$ & $\begin{array}{c}\text { Residence } \\
\text { time* } \\
\text { (years) }\end{array}$ & $\begin{array}{c}\text { Half-life* } \\
\text { (years) }\end{array}$ \\
\hline (a) & Norway spruce & 0.018 & 56 & 39 \\
& European larch & 0.012 & 83 & 58 \\
\hline (b) & Norway spruce & 0.012 & 84 & 58 \\
& European larch & 0.005 & 222 & 154 \\
\hline \multirow{2}{*}{ (c) } & Norway spruce & 0.022 & 45 & 32 \\
& European larch & 0.012 & 83 & 58 \\
\hline
\end{tabular}

* Calculated from the average decay constant.

were known the decay rates could be better assessed. Unfortunately, the fall rates of snags of the studied tree species are unknown at the investigated sites. To our knowledge, no data about fall rates of snags of either species, i.e. Picea abies (Norway spruce) or Larix decidua Mill. (European larch), are available. In this respect, the data situation in North America is much better. A good overview is given, for example, in Hilger et al. (2012) and Dixon (2015). According to Hilger et al. (2012), Engelmann spruce (Picea engelmannii Parry ex Engelm.) and subalpine larch (Larix lyallii Parl.) have similar snag fall rates. Due to morphological, ecological, and physiological similarities, we have to assume (but cannot ultimately prove) that Norway spruce and European larch should exhibit a similar reaction to Engelmann spruce and subalpine larch. As a consequence, no particular difference in the fall rate between European larch and Norway spruce is to be expected. Therefore, differences in the decay rates between European larch and Norway spruce are hypothesised not to be due to different fall rates.

Angers et al. (2012), however, observed that the wood density in snags in boreal forests already decreases after a few years. Decay rates they calculated are comparable to those in our study. The density loss in standing dead trees could be due to the activity of cerambycid larvae, while the activity of the wood decomposers, mainly fungi, was impeded in snags due to the lack of moisture. The discrepancy be- tween the macromorphology of deadwood (and consequently decay class) and the age of deadwood seems to be therefore related to the individual tree death history. Shortly after tree death, in fact, the wood is rapidly colonised by fungi (Zielonka, 2006). The CWD in classes 4 and 5 showed a relation to deadwood age that seems to be species-specific since larch CWD is older than spruce in both classes. With respect to the CWD ages in our study, classes 1-3 appear to be a single group, while classes 4 and 5 are different. The oldest sample (larch CWD) was about 244 years old a surprisingly old age for wood lying on the forest floor (i.e. not buried). Spruce CWD in decay classes 4 and 5 seems to be significantly younger than larch CWD. Few empirical assessments of time since the death of a tree have been made in Europe. Krüger et al. (2014) used both dendrochronology and radiocarbon dating to assess the time since death of Norway spruce in Bavarian forests. They estimated a total residence time of 61-62 years for this species. Our values are slightly lower. One major problem in determining the age using ${ }^{14} \mathrm{C}$ is the sometimes large age ranges obtained after calibration (due to plateaus) for samples having a pre-bomb age. We used the ranges with the highest probabilities (varying from 50 to $82.2 \%$; Table 4 ; commonly the age $1 \sigma$ range, i.e. $68 \%$ is considered) for CWD dated to the time period before the bomb peak. Consequently, this procedure introduces an uncertainty. According to Krüger et al. (2014), radiocarbon analysis and dendrochronological cross-dating revealed a similar year of tree death for samples having a post-bomb age. The results of Krüger et al. (2014) suggest that both methods are suitable for the age determination of CWD. In Atlantic Canada, Campbell and Laroque (2007) found an age of 56-84 years (depending on the investigated sites) in the latest decay stage (decay class 5; black spruce and balsam fir). Lombardi et al. (2008) estimated stumps of beech and silver fir in decay class 3 to be 55 and 59 years, which is close to our findings.

The decay rates reflect the determined ages of the CWD, and spruce therefore had a higher decay rate constant than larch. Consequently, decay rates are species specific due to, among others things, the initial differences in the physicalchemical properties of the wood of the living trees and in environmental factors. Larch has, for example, a higher density (Fig. 5) and a lower nutrient content than spruce (Petrillo 
et al., 2015). Shorohova and Kapitsa (2014) also found that decay rates can strongly vary among tree species. The decay rate (i.e. $0.032 \mathrm{y}^{-1}$ ) they found for spruce was slightly higher than that in our study (Fig. 6). The variability in the decay rates given in the literature may also arise from using different mathematical models or different methods to determine wood density or the age of the CWD. According to Hale and Pastor (1998), the decay rates of oak and maple $\operatorname{logs}$ (in a temperate forest) varied between 0.00 and $0.18 \mathrm{y}^{-1}$ (their dating of the logs, however, was based on estimates). The decay rates of tree species in a Mediterranean-climate area (Australia; Brown et al., 1996) varied in the range of 0.05 up to $0.22 \mathrm{y}^{-1}$, while in a cool-continental climate (Alban and Pastor, 1993), decay rates were 0.042 and 0.055 for red and jack pine, respectively, and 0.07 and $0.08 \mathrm{y}^{-1}$ for spruce and aspen. Fukusawa et al. (2014) estimated decay rates by using the annual input of CWD divided by the CWD accumulation, and obtained a value of $0.036 \mathrm{y}^{-1}$. With the chronosequence approach, however, the rates were of the order of $0.020-0.023 \mathrm{y}^{-1}$.

The determined decay rates for spruce and larch in our investigation seem to be very low (Table 6). As pointed out by Kruys et al. (2002), the chronosequence approach, and thus the snapshot sampling, may overestimate the CWD age and consequently residence time. Thus, the decay rate may be underestimated. It seems, however, that this error is not overwhelmingly distinct in our case or even absent. The approach according to Kruys et al. (2002) and variant (a) in Table 6 gave similar results. The regression approach (variant $b$ in Table 6) probably slightly underestimated the decay rates.

Using mass losses instead of density losses to estimate the decay rates may result in higher values, because the losses for fragmentation are added to the mineralisation losses (Yin, 1999). This might explain why our decay rate constants were lower than those in some other studies (Rock et al., 2008; Herrmann et al., 2015). Moreover, the decay rates are sensitive, at a regional scale, to climatic conditions such as temperature and precipitation (Shorohova and Kapitsa, 2014), although the decay rates for a mean annual temperature of 0 $10^{\circ} \mathrm{C}$ are, however, quite similar, and rates below $0.04 \mathrm{y}^{-1}$ are often reported (Mackensen et al., 2003). Soil temperature was found to be the main explanatory variable for differences in the decay rates of standard wood, such as aspen and pine (Risch et al., 2013). Although the data are too limited to draw a clear conclusion, some of the differences in the decay rates we observed are likely to be due to environmental factors. On south-facing sites, for instance, we found that the decay rates were slightly, but not significantly, higher than those on north-facing sites (Fig. 6), which is comparable to the observations of Shorohova and Kapitsa (2014).

Although our measured $k$ values are very low, they fit reasonably well to those of the recent compilation of Russel et al. (2015). For environments having a mean annual temperature of $<10^{\circ} \mathrm{C}$, the decay rate constants are usually $<0.1$ (median value is 0.027 for such sites). The compilation of Russel et al. (2015), however, only considers two sites having Picea abies ( $k$ values $=0.044$ and 0.027; Krankina et al., 1999; Næsset, 1999) and none for larch. Together with our results, a residence time of about 20-90 years for Picea abies in subalpine (boreal) climates might be suggested.

The concentrations of cellulose and lignin in the CWD are given as a function of time in Fig. 5. Due to the faster decomposition of cellulose, lignin is relatively enriched. Lignin, however, also decomposes with time. To unravel the decay behaviour of these compounds, a multiple-exponential model was applied (Means et al., 1985; Mackensen et al., 2003), with the general form

$x_{t}=x_{1} e^{-k_{1} t}+x_{2} e^{-k_{2} t} \ldots+x_{n} e^{-k_{n} t}$,

where $x_{t}$ is the density or mass of deadwood at a given time and $x_{1 \ldots n}$ are partitioned parameters. The portioning of cellulose and lignin is solved graphically using their mass per unit volume over time and fitting them to an exponential regression curve. From this, the half-life of cellulose or lignin in the CWD could be calculated:

$t_{1 / 2}=\frac{\ln (1 / 2)}{-k}$,

where $t_{1 / 2}$ is the half-life and $k$ is the decay constant (obtained from the exponential regression curve). Using the $k$ values in Fig. 7, the following half-lives were obtained:
a. for cellulose: 21 years (spruce) and 50 years (larch);
b. for lignin: 91 years (spruce) and 481 years (larch).

Means et al. (1985) were able to derive $k$ values for cellulose values of $0.0109-0.0117 \mathrm{y}^{-1}$ for Douglas fir logs (in a cool to temperate climate), although age determination (or estimation) was done differently. This would give rise to halflives in the range of 59-64 years. With $k$ values in the range of $0.0039-0.0045 \mathrm{y}^{-1}$ (Means et al., 1985), the half-life of lignin would be in the range of $154-178$ years. In this specific case, the overall decay rates were between 0.006 and $0.0073 \mathrm{y}^{-1}$. Although cellulose is relatively easily degradable by (micro)organisms, it may persist astonishingly long in larch trees (several decades). Lignin may have a half-life of more than hundred years. These half-lives may be shorter if the decay is related to mass losses and not to density.

In decay classes 4 and 5, the CWD starts to become more and more part of the soil. The further fate of CWD compounds strongly depends on their interaction with the mineral soil. The introduced organic matter into soils can be either further degraded or stabilised to a certain extent. The persistence of organic matter in soils is largely due to complex interactions between the organic matter and its environment, such as the interdependence of compound chemistry, reactive mineral surfaces, climate, water availability, soil acidity, soil redox state, and the presence of potential degraders in 

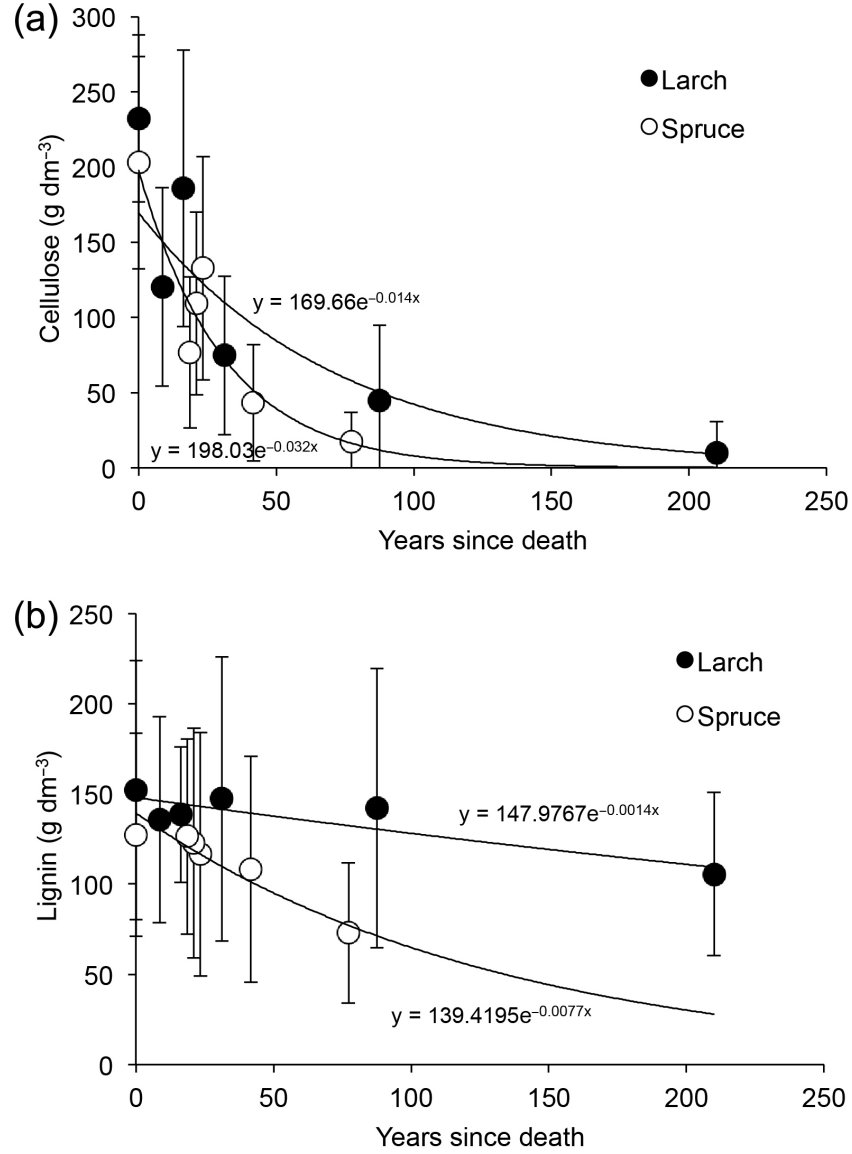

Figure 7. Empirically determined exponential regression curves (principle of multiple-exponential model) for partitioning the decay behaviour of cellulose (a) and lignin (b).

the immediate micro-environment (Schmidt et al., 2011). Together with physical protection, organo-mineral interactions are generally thought to be the main mechanism for SOM stabilisation (e.g. Nierop et al., 2002; Kleber et al., 2005; Marschner et al., 2008).

\section{Conclusions}

The first three decay classes do not seem to reflect the age of the CWD, but they are relevant for the description of its decay stage. The time lag between the death of a standing tree and its contact with the soil overshadows a clear age trend. Taking classes 1-3 as one group and relating them to the decay classes 4 and 5, a time trend with increasing decay stage can then be detected. This time trend also closely correlates with the wood density, and the cellulose and lignin content. The oldest CWD age of a larch tree reached the considerable age of 244 years. We used a chronosequence approach and applied several calculation techniques to estimate the overall decay rate constants of European larch and Norway spruce. The stage-based matrix model of Kruys et al. (2002) that cor- rects for sampling bias was in good agreement with the oftenused single-negative-exponential model. The regression approach probably underestimated slightly the decay rates. The decay rate constant for spruce seems to be in the range of $0.018-0.022\left(\mathrm{y}^{-1}\right)$ and for larch it is about $0.012\left(\mathrm{y}^{-1}\right)$. The rates seemed to be slightly higher on south-facing sites (although this was not statistically significant). An effect of the altitude on the decay rates was, however, not discernible. Using the dating approach (dendrochronology and ${ }^{14} \mathrm{C}$ dating), the behaviour of cellulose and lignin as a function of time could be assessed. Our findings demonstrate that lignin in larch may persist particularly long, with a mean residence time of $>100$ years. This indicates that turnover rates of CWD organic matter are even in a comparable range to that of SOM.

More empirical data are, however, needed to ascertain our findings. A major issue is that fall rates between $\mathrm{Eu}-$ ropean larch and Norway spruce could not be compared. Furthermore, the preparation and precise dating of CWD is time-consuming, cost-intensive, and in some cases also difficult (particularly samples with a pre-bomb age in decay classes 4 and 5). Since CWD represents an important forest carbon pool, improving the informative potential of the decay classes (including the dating of the CWD) would contribute to sustainable forest management and make carbon accounting easier. 


\section{Appendix A}

Table A1. Radiocarbon data of the deadwood samples of the decay classes 1-3.

\begin{tabular}{|c|c|c|c|c|c|c|c|c|c|c|c|}
\hline $\begin{array}{l}\text { UZH } \\
\text { number }\end{array}$ & $\begin{array}{l}\text { ETH } \\
\text { number }\end{array}$ & Sample code & Site & Tree species & $\begin{array}{l}\text { Decay } \\
\text { class }\end{array}$ & $\begin{array}{l}\mathrm{C} 14 \\
\text { age }\end{array}$ & $\pm 1 \sigma$ & $\begin{array}{c}\delta^{13} \mathrm{C} \\
\% o\end{array}$ & $\begin{array}{c} \pm \delta^{13} \mathrm{C} \\
\% o\end{array}$ & $\begin{array}{l}\text { Cal AD } \\
\pm 1 \sigma\end{array}$ & $\begin{array}{c}\text { Average } \\
\text { age } \\
\text { years* }\end{array}$ \\
\hline UZ-6258 & ETH-60741 & L_10_c1_1 & S7 & European larch & 1 & -435 & 25 & -25.7 & 1 & 2006-2009 & 6 \\
\hline UZ-6260 & ETH-60743 & S07_dc2_92 & S7 & European larch & 2 & -590 & 25 & -26.9 & 1 & 2002-2004 & 10 \\
\hline UZ-6261 & ETH-60744 & S07_dc3_96 & S7 & European larch & 3 & -545 & 25 & -26.4 & 1 & 2003-2005 & 9 \\
\hline UZ-6262 & ETH-60745 & S09_cl3_46 & S9 & European larch & 3 & -2865 & 25 & -29.3 & 1 & 1973-1974 & 40 \\
\hline UZ-6263 & ETH-60746 & S09_cl3_48 & S9 & European larch & 3 & -2775 & 25 & -23.8 & 1 & 1962-1974 & 45 \\
\hline
\end{tabular}

* Calculated as the mean value between the maximum and minimum age $(1 \sigma)$. For this range of years $(1 \sigma)$, associated probabilities summed to $68.2 \%$. 
Acknowledgements. This study is part of the DecAlp DACH (project no. 205321L_141186). J. Ascher has been funded by the Fonds zur Förderung der wissenschaftlichen Forschung (FWF) Austria (project I989-B16). We are indebted to Fabio Angeli of the "Ufficio distrettuale forestale di Malé" and his team of foresters for their support in the field. We would also like to thank Leonora Di Gesualdo for her help in the sampling wood cores and Michelle Kovacic for preparing samples for radiocarbon dating. We are grateful to Silvia Dingwall for the English corrections. Furthermore, we gratefully acknowledge the constructive suggestions of the referees (one anonymous reviewer and J. Schöngart) and two readers (T. Kahl and V.-A. Angers), which helped in improving the manuscript.

Edited by: J. Schöngart

\section{References}

Alban, D. H. and Pastor, J.: Decomposition of aspen, spruce, and pine boles on two sites in Minnesota, Can. J. Forest Res., 23, 1744-1749, doi:10.1139/x93-220, 1993.

Angers, V. A., Drapeau, P., and Bergeron, Y.: Mineralization rates and factors influencing snag decay in four North American boreal tree species, Can. J. Forest Res., 42, 157-166, doi:10.1139/X11167, 2012.

Barbati, A., Marchetti, M., Chirici, G., and Corona, P.: European forest types and forest Europe SFM indicators: Tools for monitoring progress on forest biodiversity conservation, Forest Ecol. Manag., 321, 145-157, doi:10.1016/j.foresco.2013.07.004, 2014.

Bond-Lamberty, B. and Gower, S. T.: Decomposition and fragmentation of coarse woody debris: Re-visiting a boreal black spruce chronosequence, Ecosystems, 11, 831-840, doi:10.1007/s10021008-9163-y, 2008.

Boettger, T., Haupt, M., Knoller, K., Weise, S. M., Waterhouse, J. S., Rinne, K. T., Loader, N. J., Sonninen, E., Jungner, H., Masson-Delmotte, V., Stievenard, M., Guillemin, M. T., Pierre, M., Pazdur, A., Leuenberger, M., Filot, M., Saurer, M., Reynolds, C. E., Helle, G., and Schleser, G. H.: Wood Cellulose Preparation Methods and Mass Spectrometric Analyses of $\delta^{13} \mathrm{C}, \delta^{18} \mathrm{O}$, and Nonexchangeable $\delta^{2} \mathrm{H}$ Values in Cellulose, Sugar, and Starch:? An Interlaboratory Comparison, Anal. Chem., 79, 4603-4612, doi:10.1021/ac0700023, 2007.

Bronk Ramsey, C.: Development of the radiocarbon calibration program, Radiocarbon, 43, 355-363, 2001.

Bronk Ramsey, C.: Bayesian analysis of radiocarbon dates, Radiocarbon 51, 337-360, 2009.

Brown, S., Mo, J., McPherson, J. K., and Bell, D. T.: Decomposition of woody debris in Western Australian forests, Can. J. Forest Res., 26, 954-966, doi:10.1139/x26-105, 1996.

Busse, M. D.: Downed bole-wood decomposition in lodgepole pine forests of central Oregon, Soil Sci. Soc. Am. J., 58, 221-227, 1994.

Campbell, L. J. and Laroque, C. P.: Decay progression and classification in two old-growth forests in Atlantic Canada, Forest Ecol. Manag., 238, 293-301, doi:10.1016/j.foreco.2006.10.027, 2007.

Carrer, M. and Urbinati, C.: Long-term change in the sensitivity of tree-ring growth to climate forcing in Larix decidua, New
Phytol., 170, 861-872, doi:10.1111/j.1469-8137.2006.01703.x, 2006.

Dence, C. W. and Lin, S. Y. (Eds.): Introduction, in: Methods in lignin chemistry, Springer, Heidelberg, 1-19, 1992.

Di Cosmo, L., Gasparini, P., Paletto, A., and Nocetti, M.: Deadwood basic density values for national-level carbon stock estimates in Italy, Forest Ecol. Manag., 295, 51-58, doi:10.1016/j.foreco.2013.01.010, 2013.

Dixon, G. E.: Essentials FVS: A User's Guide to the Forest Vegetation Simulator. United States Department of Agriculture, US Forest Service, Fort Collins CO, 2015.

Egli, M., Mirabella, A., Sartori, G., Zanelli, R., and Bischof, S.: Effect of north and south exposure on weathering rates and clay mineral formation in Alpine soils, Catena 67, 155-174, doi:10.1016/j.catena.2006.02.010, 2006.

Esper, J., Büntgen U., Frank, D. C., Nievergelt, D., and Liebhold, A.: 1200 years of regular outbreaks in alpine insects, P. Roy. Soc. Lond. B Bio., 274, 671-679, doi:10.1098/rspb.2006.0191, 2007.

Hale, C. M. and Pastor, J.: Nitrogen content, decay rates, and decompositional dynamics of hollow versus solid hardwood logs in hardwood forests of Minnesota, U.S.A., Can. J. Forest Res., 28, 1276-1285, doi:10.1139/cjfr-28-9-1276, 1998.

Harmon, M. E., Franklin, J. F., Swanson, F. J., Sollins, P., Gregory, S. V., Lattin, J. D, Anderson, N. H., Cline, S. P., Aumen, N. G., Sedell, J. R., Lienkaemper, G. W., Cromack, K., and Cummins, K. W.: Ecology of coarse woody debris in temperate ecosystems, Adv. Ecol. Res., 15, 133-302, doi:10.1016/S00652504(08)60121-X, 1986.

Herrmann, S., Kahl, T., and Bauhus, J.: Decomposition dynamics of coarse woody debris of three important central European tree species, Forest Ecosystems, 2, doi:10.1186/s40663-015-0052-5, 2015.

Hilger, A. B., Shaw, C-.H., Metsaranta, J. M., and Kurz, W. A.: Estimation of snag carbon transfer rates by ecozone and lead species for forests in Canada, Ecol. Appl., 22, 2078-2090, doi:10.1890/11-2277.1, 2012.

Holmes, R. L., Adams, R. K., and Fritts, H. C.: Tree-ring chronologies of Western North America: California, Eastern Oregon and Northern Greate Basin, with procedures used in chronology development work, including users manuals for computer programs COFECHA and ARSTAN, Chronology series VI, Laboratory of Tree-Ring Research, University of Arizona, Tucson, 182 pp., 1986.

Hua, Q., Barbetti, M., and Rakowski, A. Z.: Atmospheric radiocarbon for the period 1950-2010, Radiocarbon, 55, 2059-2072, doi:10.2458/azu_js_rc.v55i2.16177, 2013.

Hunter, M. L.: Wildlife, forests and forestry: principles of managing forests for biological diversity, Prentice Hall, Englewood Cliffs, NJ, USA, 370 pp., 1990.

IUSS Working Group WRB: World Reference Base for Soil Resources 2014. International Soil Classification System for Naming Soils and Creating Legends for Soil Maps, FAO, Rome, World Soil Resources Reports No. 106, 2014.

Jebrane, M., Pockrandt, M., and Terziev, N.: Natural durability of selected larch and Scots pine heartwoods in laboratory and field tests, Int. Biodeter. Biodegr., 91, 88-96, doi:10.1016/j.ibiod.2014.03.018, 2014.

Jenny, H., Gessel, S. P., and Bingham, F. T.: Comparative study of decomposition of organic matter in temperate and trop- 
ical regions, Soil Sci., 68, 419-432, doi:10.1097/00010694200606001-00017, 1949.

Kaennel, M. and Schweingruber, F. H.: Multilingual glossary of dendrochronology. Terms and definitions in English, German, French, Spanish, Italian, Portuguese and Russian, Swiss Federal Institute for Snow, Forest and Landscape Research, Haupt, Bern, Switzerland, 1995.

Kleber, M., Mikutta, R., Torn, M. S., and Jahn, R.: Poorly crystalline mineral phases protect organic matter in acid subsoil horizons, Eur. J. Soil Sci., 56, 717-725, doi:10.1111/j.13652389.2005.00706.x, 2005

Krankina, O. N., Harmon, M. E., and Griazkin, A. V.: Nutrient stores and dynamics of woody detritus in a boreal forest: modeling potential implications at the stand level, Can. J. Forest Res., 29, 20-32, doi:10.1139/x98-162, 1999.

Krüger, I., Muhr, J., Hartl-Meier, C., Schulz, C., and Borken, W.: Age determination of coarse woody debris with radiocarbon analysis and dendrochronological cross-dating, Eur. J. For. Res., 133, 931-939, doi:10.1007/s10342-014-0810-x, 2014.

Kruys, N., Jonsson, B. G., and Ståhl, G.: A stage-based matrix model for decay-class dynamics of woody debris, Ecol. Appl., 12, 773-781, 2002.

Kueppers, L. M., Southon, J., Baer, P., and Harte, J.: Dead wood biomass and turnover time, measured by radiocarbon, along a subalpine elevation gradient, Oecologia, 141, 641-651, doi:10.1007/s00442-004-1689-x, 2004.

Lombardi, F., Cherubini, P., Lasserre, B., Tognetti, R., and Marchetti, M.: Tree rings used to assess time since death of deadwood of different decay classes in beech and silver fir forests in the central Apennines (Molise, Italy), Can. J. Forest Res., 38, 821-833, doi:10.1139/X07-195, 2008.

Lombardi, F., Cherubini, P., Tognetti, R., Cocozza, C., Lasserre, B., and Marchetti, M.: Investigating biochemical processes to assess deadwood decay of beech and silver fir in Mediterranean mountain forests, Ann. For. Sci, 70, 101-111, doi:10.1007/s13595012-0230-3, 2013.

Mackensen, J., Bauhus, J., and Webber, E.: Decomposition rates of coarse woody debris - A review with particular emphasis on Australian tree species, Aust. J. Bot., 51, 27- 37, doi:10.1071/BT02014, 2003.

Marschner, B., Brodowski, S., Dreves, A., Gleixner, G., Gude, A., Grootes, P. M., Hamer, U., Heim, A., Jandl, G., Ji, R., Kaiser, K., Kalbitz, K., Kramer, C., Leinweber, P., Rethemeyer, J., Schäffer, A., Schmidt, M. W. I., Schwark, L., and Wiesenberg, G. L. B.: How relevant is recalcitrance for the stabilization of organic matter in soils?, J. Plant Nutr. Soil Sc. 171, 91-110, doi:10.1002/jpln.200700049, 2008.

Means, J. E., Cromack, K., and MacMillan, P. C.: Comparison of decomposition models using wood density of Douglas-fir logs, Can. J. Forest Res., 15, 1092-1098, doi:10.1139/x85-178, 1985.

Melin, Y., Petersson, H., and Nordfjell, T.: Decomposition of stump and root systems of Norway spruce in Sweden - A modelling approach, For. Ecol. Manag. 257, 1445-1451, 2009.

Minderman, G.: Addition, decomposition and accumulation of organic matter in forests, J. Ecol., 56, 355-362, doi:10.2307/2258238, 1968.

Müller, J. and Bütler, R.: A review of habitat thresholds for dead wood: a baseline for management recommendations in European forests, Eur. J. For. Res., 129, 981-992, doi:10.1007/s10342-0100400-5, 2010.

Müller-Using, S. and Bartsch, N.: Decay dynamic of coarse and fine woody debris of a beech (Fagus sylvatica L.) forest in Central Germany, Eur. J. For. Res., 128, 287-296, doi:10.1007/s10342009-0264-8, 2009.

Næsset, E.: Decomposition rate constants of Picea abies logs in southeastern Norway, Can. J. Forest Res., 29, 372-381, doi:10.1139/x99-005, 1999.

Nierop, K. G. J., Jansen, B., and Verstraten, J. A.: Dissolved organic matter, aluminium and iron interactions: precipitation induced by metal/carbon ratio, $\mathrm{pH}$ and competition, Sci. Total Environ., 300, 201-211, doi:10.1016/S0048-9697(02)00254-1, 2002.

Olson, J. S.: Energy storage and the balance of producers and decomposers in ecological systems, Ecology, 44, 322-331, doi: $10.2307 / 1932179,1963$.

Parker, W. H.: Larix, in: Flora of North America North of Mexico, edited by: Flora of North America Editorial Committee, Oxford University Press, 2, 366-368, 1993.

Palviainen, M., Finén, L., Laiho, R., Shorohova, E., Kapitsa, E., and Vanha-Majamaa, I.: Phosphorus and base cation accumulation and release patterns in decomposing Scots pine, Norway spruce and silver birch stumps, Forest Ecol. Manag., 260, 1478-1489, doi:10.1016/j.foreco.2010.07.046, 2010.

Petrillo, M., Cherubini, P., Sartori, G., Abiven, S., Ascher, J., Bertoldi, D., Camin, F., Barbero, A., Larcher, R., and Egli, M.: Decomposition of Norway spruce and European larch coarse woody debris (CWD) in relation to different elevation and exposition in an Alpine setting, iForest, 9, 154-164, doi:10.3832/ifor1591-008, 2015.

Reimer, P. J., Bard, E., Bayliss, A., Beck, J. W., Blackwell, P. G., Bronk Ramsey, C., Buck, C. E., Cheng, H., Edwards, R. L., Friedrich, M., Grootes, P. M., Guilderson, T. P., Haflidason, H., Hajdas, I., Hatté, C., Heaton, T. J., Hoffmann, D. L., Hogg, A. G., Hughen, K. A., Kaiser, K. F., Kromer, B., Manning, S. W., Nui, M., Reimer, R. W., Richards, D. A., Scott, E. M., Southon, J. R., Staff, R. A., Turney, C., and van der Plicht, J.: IntCal13 and Marine13 radiocarbon age calibration curves $0-50,000$ years cal BP, Radiocarbon, 55, 1869-1887, doi:10.2458/azu_js_rc.55.16947, 2013.

Risch, C. A., Jurgensen, F. M., Page-Dumroese, D. S., and Schütz, M.: Initial turnover rates of two standard wood substrates following land-use change in subalpine ecosystems in the Swiss Alps, Can. J. Forest Res., 43, 901-910, doi:10.1139/cjfr-20130109, 2013.

Rock, J., Badeck, F., and Harmon, M. E.: Estimating decomposition rate constants for European tree species from literature sources, Eur. J. For. Res., 127, 301-313, doi:10.1007/s10342-008-0206-x, 2008.

Russel, M. B., Fraver, S. F., Aakala, T., Gove, J. H., Woodall, C. W., D'Amato, A. W., and Ducey, M. J.: Quantifying carbon stores and decomposition in dead wood: A review, Forest Ecol. Manag, 350, 107-128, doi:10.1016/j.foreco.2015.04.033, 2015.

Sandström, F., Petersson, H., Kruys, N., and Ståhl, G.: Biomass conversion factors (density and carbon concentration) by decay classes for dead wood of Pinus sylvestris, Picea abies and Betula spp. in boreal forests of Sweden. Forest Ecol. Manag., 243, 19-27, 2007. 
Sboarina, C. and Cescatti, A.: Il clima del Trentino - Distribuzione spaziale delle principali variabili climatiche, Report 33, Centro di Ecologia Alpina Monte Bondone, Trento, Italy, 2004.

Schmidt, M. W. I., Torn, M. S., Abiven, S., Dittmar, T., Guggenberger, G., Janssens, I. A., Kleber, M., Kögel-Knabner, I., Lehmann, J., Manning, D. A. C., Nannipieri, P., Rasse, D. P., Weiner, S., and Trumbore, S. E.: Persistence of soil organic matter as an ecosystem property, Nature, 478, 49-56, doi:10.1038/nature10386, 2011.

Shorohova, E. and Kapitsa, E.: Influence of the substrate and ecosystem attributes on the decomposition rates of coarse woody debris in European boreal forests, Forest Ecol. Manag., 315, 173-184, doi:10.1016/j.foreco.2013.12.025, 2014.

Wider, R. K. and Lang, G. E.: A critique of the analytical methods used in examining decomposition data obtained from litter bags, Ecology, 63, 1636-1642, doi:10.2307/1940104, 1982.
Wigley, T. M. L., Briffa, K. R., and Jones, P. D.: On the average value of correlated time series, with applications in dendroclimatology and hydrometeorology, J. Clim. Appl. Meteorol., 23, 201-213, doi:10.1175/15200450(1984)023<0201:OTAVOC>2.0.CO;2, 1984.

Yatskov, M., Harmon, M. E., and Krankina, O. N.: A chronosequence of wood decomposition in the boreal forests of Russia, Can. J. Forest Res., 33, 1211-1226, doi:10.1139/X03-033, 2003.

Yin, X.: The decay of forest woody debris: numerical modelling and implications based on some 300 data cases from North America, Oecologia, 121, 81-98, doi:10.1007/s004420050909, 1999.

Zielonka, T.: When does dead wood turn into a substrate for spruce replacement?, J. Veg. Sci., 17, 739-746, doi:10.1111/j.16541103.2006.tb02497.x, 2006. 